\title{
Internal and external barriers to energy efficiency: which role for policy interventions?
}

\author{
Cristina Cattaneo 1
}

Received: 24 April 2018 / Accepted: 9 January 2019/Published online: 13 February 2019

(C) The Author(s) 2019

\begin{abstract}
This paper reviews the empirical literature that provides a correlation between the different barriers to energy efficiency and consumer behavior related to two domains. It evaluates behavior related to energy curtailment, which represents routine, repetitive effort to decrease consumption on a day-to-day basis. It also considers behavior related to investments, which are one time actions such as purchasing new energy efficiency technologies. The paper also reviews the existing literature that assesses the effect of policies on energy use and investment in energy efficiency technologies. By surveying the relevant research, this paper has two objectives. First, it discusses the impact of different barriers on energy efficiency, and second, it combines policy interventions with barriers related to both energy use and investment in energy efficiency technologies.
\end{abstract}

Keywords Energy efficiency gap · Energy policy · Behavioral economics

\section{Introduction}

EU countries agreed on a 2030 framework for climate and energy, which sets challenging targets for the

C. Cattaneo $(\bowtie)$

Centro Euro-Mediterraneo sui Cambiamenti Climatici and Fondazione Eni Enrico Mattei (FEEM), RFF-CMCC European Institute on Economics and the Environment (EIEE), Via Bergognone 34, 20144 Milan, Italy

e-mail: cristina.cattaneo@eiee.org
European Union post-2020. The European Council endorsed three targets, with one being a binding commitment to improve energy efficiency. Energy efficiency can deliver a wide range of benefits to the economy and society. The ability to increase energy efficiency depends on a plurality of factors, not only on the availability of cheap technologies or on policy interventions but to a large extent on the behavioral choices of users. However, the evidence is that individuals underinvest in energy-efficient technologies with adoption rate of households being too low. The existing literature has largely searched the explanations for such underinvestment and correlated high implicit discount rates (see for example, Hirst and Brown 1990; Jaffe and Stavins 1994).

The current paper reviews the empirical research that provides a correlation between the different barriers to energy efficiency and consumer behavior related to two domains. The first domain is behavior related to energy curtailment, which represents routine, repetitive effort to decrease consumption on a day-to-day basis. The second is behavior related to investments, which are one time actions such as purchasing new energy efficiency technologies and modifying a building or a house. While some types of barriers are well known (for example, barriers related to market failures), barriers that pertain to preferences and irrational behavior are less studied. A better understanding of the exact impacts of the latter on energy efficiency is still needed (Gillingham et al. 2009). By surveying the relevant literature, the first objective of the present paper is to fill in the existing gap in research and discuss the impact 
on energy efficiency of different barriers, in particular barriers that pertain to preferences and irrational behavior. If policy makers were only to consider market or institutional barriers and not individual barriers to energy efficiency, they would limit the potential to improve energy efficiency. This is because energy efficiency is largely influenced by preferences and behavior factors.

By reviewing the relevant literature, the second objective of the paper is to combine policy interventions and barriers related to both energy use and investment in energy efficiency technologies. In doing so, the paper investigates the efficacy of the existing "nudges" approaches, which are low-cost motivational and persuasion strategies (Schultz et al. 2007; Goldstein et al. 2008). Moreover, the paper reviews the penetration of behavioral sciences principles (such as referencedependence and non-linear probability weighting, rational inattention, bounded rationality, present bias and myopia, and status quo bias) into this type of programs. This is one of the first contributions that combine the main findings of different disciplines, from economics to psychology. This paper focuses primarily on the residential sector. Despite being interesting, conducts related to organizations, such as industrial and commercial firms, are beyond the scope of the present paper.

The remainder of the paper is organized as follows. Through a literature review, the "Literature review of the impact of barriers on behavior" section presents the empirical evidence of the impact of the barriers on adoption and energy use, while the "Literature review on policy interventions" section describes the different policies available in the energy efficiency domain and discusses their relevance in addressing the barriers to energy efficiency. The "Discussion" section provides a summary of the results, and the "Summary and conclusions" section concludes the paper.

\section{Literature review of the impact of barriers on behavior}

Various barriers to the adoption of energy efficiency technologies have been identified. ${ }^{1}$ Schleich et al. (2016) provide a framework that distinguishes the different factors underlying the high implicit discount rates

\footnotetext{
${ }^{1}$ See Gerarden et al. (2017) for a review and Gerarden et al. (2015) for a methodological overview that help quantifying the precise magnitude of the energy efficiency gap.
}

in internal and external barriers. Internal barriers relate to individual preferences and behavior. External barriers mainly depend on institutional settings. ${ }^{2}$ I apply the same framework throughout this paper, because of its clarity and completeness. Moreover, the same types of barriers are found to influence both investment and energy use.

Internal barriers and adoption or energy use

According to Schleich et al. (2016), internal barriers to energy efficiency are related to preferences and predictable (ir)rational behavior. Benefits and costs of an investment vary across individuals and if an investment is profitable for one, it may not be so for another. The heterogeneity of the agents plays a great role in explaining the variation in energy-efficient behavior as individuals differ in their time, risk, and proenvironmental preferences.

\section{Preferences}

Time preferences describe the level of (im)patience of an individual, her present or future orientation. Time preferences are reflected in time discounting, namely how the consumers value the future relative to the present. In the context of energy-efficient choices, persons with higher discount rates are expected to be less willing to carry out energy-saving investments, because they devalue future rewards, expressed in terms of energy savings.

Time preferences are typically elicited by observing actual energy-saving behavior (Frederick et al. 2002). Only few studies measure individual discount rates first, and only then correlate these discount rates to investment and consumption behavior related to energy efficiency. Newell and Siikamäki (2015) apply this sequential approach and confirm that impatient individuals, those with higher discount rates, attach a lower value to the operating cost savings of an energyefficient appliance which occur in the future. Liebermann and Ungar (1997, 2002) apply a similar framework and conclude that people with lower

\footnotetext{
${ }^{2}$ The divide between internal and external barriers is the result of theories that assume that people are constrained or influenced by external forces frequently beyond their comprehension and control (Sovacool and Hess 2017). However, human action and social structure are mutually co-constructed and this may challenge the distinction between internal and external factors.
} 
discount rates tend to select more energy-efficient and initially more expensive air-conditioning systems, while people with higher discount rates tend to prefer cheaper and less energy-efficient devices. Bradford et al. (2014) find that more patient individuals are more likely to have installed energy-efficient lighting and use less air conditioning in summer. Fischbacher et al. (2015) find that time preferences do not influence investment in renovation but homeowners who care more about the future consume less energy. Bruderer Enzler et al. (2014) relate discount rates to various energy-saving behaviors. They find mixed results, with low discount rates being correlated with only some of the behaviors considered.

Given that some degree of uncertainty surrounds the benefits of an energy efficiency investment, due to uncertain prospects of future cost savings or uncertain technology performance, preferences related to risk are another internal barrier typically influencing investments. ${ }^{3}$ Risk preferences vary among individuals, but, most importantly, the same person can change her love and aversion for risk, depending on what is at stake. People tend to be less risk averse for low-stakes than for large-stakes gambles. This behavior is known as the "peanuts effect" (Weber and Chapman 2005). Therefore, more risk-averse agents are less willing to adopt energy-efficient appliances, retrofit their homes, or purchase hybrid automobiles (Erdem et al. 2010; Farsi 2010; Qiu et al. 2014; Fischbacher et al. 2015).

Pro-environmental preferences are a third factor affecting behavior in the energy domain. People may choose to act pro-environmentally because they want to protect the environment and value environmental quality more than their personal comfort. Values are antecedents of environmental preferences, intentions, and behavior and guide principles in everyone's life (Schwartz 1992). They are important drivers of actions, with some values limiting pro-environmental actions and others promoting them (Dunlap et al. 1983). Individuals endorse four different values: hedonic, egoistic, altruistic, and biospheric (Steg and De Groot 2012). While altruistic and biospheric values are positively correlated with pro-environmental behavior, hedonic and egoistic values constrain pro-environmental behaviors (de Groot and Steg 2008; Steg et al. 2014).

\footnotetext{
${ }^{3}$ Interestingly, there is a correlation between risk and time preferences. Typically, high risk aversion is associated with low discounting (Sutter et al. 2013; Rodriguez-Lara and Ponti 2017).
}

Do environmental preferences explain consumer behavior in energy efficiency? The evidence is mixed and it is so for two reasons. First, because environmental preference can be measured either through attitudes or through effective behavior. There are a number of papers that find a positive correlation between proenvironmental attitudes, measured through stated preferences, and energy efficiency related to both investment and energy use (Kotchen and Moore 2007, 2008; Di Maria et al. 2010; Ek and Söderholm 2010; van der Werff et al. 2013; Fischbacher et al. 2015; Harding and Rapson 2017). On the contrary, other studies find that only environmental behavior is correlated with energy efficiency, whereas attitudes are not (Lange et al. 2014; Ramos et al. 2016). Ramos et al. (2016) notice that measures of environmental attitudes elicited through stated preferences may not reflect true environmental preferences because of "compliance/social desirability bias." This bias arises when respondents tend to manifest a higher propensity to be pro-environment due to the influence of social norms. This may explain why pro-environmental attitudes do not always translate into actual investment in energy efficiency or energy-saving actions.

The second reason for mixed evidence is due to the different types of behavior considered. Some actions, such as energy consumption or household temperature choice, are private information, which are unobserved by other people such as neighbors. Other actions, such as investment in solar panel or purchase of hybrid cars are visible to others. In the case of green conspicuous products, the investment may be undertaken because of prestige and not by the desire to behave pro-environmentally. The adoption of green products is believed to enhance social status, particularly when it is costly, as it signals to others the availability of sufficient resources to make altruistic sacrifices (Griskevicius et al. 2010). Moreover, people tend to do what is socially approved. This evidence has been largely confirmed in the case of green cars and solar panels (Kahn 2007; Bollinger and Gillingham 2012; Sexton and Sexton 2014).

\section{(Ir)rational behavior}

Behavioral economics has drawn attention to numerous cases where individuals behave differently from the expectations of the neoclassical economic theories. Consumer behavior is complex and rarely consistent with the assumption of fully rational agents. Many 
behavioral explanations exist, but the most powerful and pervasive ones to influence energy usage and investment are (Laibson and List 2015; Hobman et al. 2016) (1) reference-dependence and non-linear probability weighting, (2) rational inattention, (3) bounded rationality, (4) present bias and myopia, and (5) status quo bias.

People tend to strongly prefer avoiding losses to achieving gains, and therefore, weight losses more heavily than equal-sized gains (Kahneman and Tversky 1979). This implies that simply framing a decision as a choice between losses rather than a choice between gains can reverse preferences, everything else is equal (Wilson and Dowlatabadi 2007). This phenomenon is called loss aversion or reference dependence because individuals evaluate the benefits and costs of a decision relative to a reference point. This insight has been formalized in the prospect theory of decision-making, which was developed to explain some of the observed violations of the expected utility theory (Kahneman and Tversky 1979). Another behavior formalized by the prospect theory is that people tend to overweight small probabilities and underweight moderate and large probabilities so that they end up using nonlinear probability weighting (Frederick et al. 2002). Loss-version, reference-dependence, and non-linear probability weighting have implications for energyefficient choices, in particular in the context of energy use. For example, Harding and Hsiaw (2014) analyze individual behavior with respect to a non-binding goal setting program, aimed at reducing energy consumption. They find support for the presence of referencedependent preferences. Moreover, they find that individuals with reference-dependent preferences tend to reduce energy use once enrolled in the goal setting program. This is because the goal acts as a reference point, and people derive utility directly from comparing their consumption against this goal.

Rational inattention is another behavioral constraint to energy efficiency. Consumers have limited attention and this may contribute to systematically underweight certain information or product attributes, in particular those that are less salient (Gerarden et al. 2017). Given that consumers are less attentive to operating costs compared with purchase prices, rational inattention can lead to low investment in energy-efficient products. Allcott (2011a) confirms that vehicle buyers make their decisions without considering fuel costs. Busse et al. (2013) and Allcott and Wozny (2014) report that consumers tend to undervalue changes in expected future energy costs, although the undervaluation is not large. Sallee et al. (2016), on the contrary, report that future fuel costs are not undervalued. Rational inattention may also have an impact on energy conservation. Cohen et al. (2017) find that consumers underestimate future energy savings and therefore increase energy use. It should be noted that the use of limited attention when choosing among different durable goods could be the result of a rational choice. A proper valuation of energy efficiency requires time and effort which may not be justified when consumers have strong preferences regarding other product attributes (Sallee 2014).

People face cognitive constraints and limitations because of bounded rationality. There are limits in human capacity to process and evaluate information. Therefore, in complex situations, characterized for example, by an overload of information, people rely on a simple counting heuristic and rules of thumb that help simplifying the decision-making process (Gigerenzer and Gaissmaier 2011). In this respect, the apparent irrational behavior could derive not from too little information, but from people being unable to process all available information, because of cognitive constraints (Simon 1982). Camilleri and Larrick (2014) find that, given bounded rationality, the decision-making is less effortful if the problem representation matches the problemsolving processes. For example, information on fuel consumption rather than fuel costs and the use of a more comprehensive mileage scale increase preferences towards fuel-efficient vehicles. Ungemach et al. (2017) confirm that people often apply simple heuristics when choosing between cars, and they are influenced by highly correlated attributes, rather than their meaning. Providing multiple translations of energy efficiency metrics could help guide behavior.

Present bias and myopia are other behavioral factors that influence both energy usage and investment. Present bias refers to a situation where a discount rate is not constant and changes over time. ${ }^{4}$ Individuals appear to discount the future at a much higher rate in the short than in the long term. As the future gets closer, individuals display reversals of preferences. This behavior has been formalized through a (quasi) hyperbolic time discounting function (Laibson 1997; Frederick et al. 2002). Individuals also display myopia, i.e., a lack of foresight (Strotz 1955). Future pleasure is valued on a

\footnotetext{
${ }^{4}$ On the contrary, time preferences discussed in the "Preferences" section indicate whether a person has a high or low discount rate.
} 
diminished scale compared with present pleasure. In the case of energy efficiency, it could be that the future receives very little weight, not because individuals do not care about the environment, but because of the high uncertainty regarding the future utility derived from undertaking pro-environmental behaviors. The model of myopia predicts reversals of preferences similar to the ones predicted by theories of present bias. A test on the impacts of present bias and myopia on energy use is provided by Harding and Hsiaw (2014). The authors find that present-biased agents consume more electricity than consumers who are not present-biased before joining a goal setting program. Bradford et al. (2014) find that present-biased individuals are less likely to have a car with high fuel economy, live in a well-insulated residence, and more likely to keep their homes cooler in summer. On the contrary, they report that present bias is not statistically significant correlated to willingnessto-pay for compact fluorescent lightbulbs. This last finding is in agreement with Allcott and Taubinsky (2015), where consumers with present bias do not have lower demand for compact fluorescent lightbulbs.

Another individual behavior that has implications for energy-efficient choices is the status quo bias, also called the endowment effect (Kahneman et al. 1991). Agents tend to stick to the default setting and display preferences for the current state. Decisions are postponed and this confers inertia to the decision process. ${ }^{5}$ The status quo and the default option tend to be favored also because individuals display an anchoring bias, whereby any arbitrary framing, such as a number, received before making a decision, tends to bias the answers towards this initial anchoring point (Tversky and Kahneman 1974). Macey and Brown (1983) suggest that past experience is a determinant of intention and actual behavior. Therefore, habits can as well constrain pro-environmental behavior if past repetitive behavior was not in favor of energy conservation. Ek and Söderholm (2010) suggest a strong presence of inertia in household decision-making concerning electricity use. Brennan (2007) observed reluctance to switch from an incumbent electricity supplier to an entrant. The status quo bias can be reinforced by uncertainty. Alberini et al. (2013) report that individuals tend to

\footnotetext{
$\overline{5}$ According to Samuelson and Zeckhauser (1988), there are three main explanations for the status quo bias: transition costs and/or uncertainty; cognitive misperceptions; psychological commitment stemming from misperceived sunk costs, regret avoidance, or a drive for consistency.
}

prefer the status quo of no renovation in case of future energy-price uncertainty.

In many circumstances, it is difficult to distinguish the implications of one behavioral factor from another. For example, there is an evidence that consumers value future savings less than the initial investment costs (Köszegi and Rabin 2006) but this may be due to both inattention and loss aversion. Savings occurring in the future are undervalued because they are less salient, and this is due to rational inattention. It could also be that investment costs are evaluated as a loss and are weighted more than gains, because of reference dependence. Moreover, both rational inattention and myopia can explain why consumers undervalue changes in energy costs that will occur in the future, or do not consider (future) fuel costs when choosing between vehicles. ${ }^{6}$

\section{External barriers and adoption or energy use}

According to Schleich et al. (2016), external barriers are factors external to the decision maker and depend on market failures and institutional settings. Capital market failures, such as liquidity constraints, are an example of external barriers as some individuals do not have access to capital to invest in energy efficiency technologies (Gillingham et al. 2009). When owners need to rely on capital markets to finance costly investment and if those markets do not function efficiently, then credit constraints may limit adoption. This happens even if expected future savings are higher than the costs. Palmer et al. (2012) document that lenders may not offer loans for energy efficiency investments because of credit risk, high transaction costs, and asymmetric information.

Another external barrier is represented by information problems. If consumers lack information on product availability and energy-efficient attributes, such as potential savings, they tend to invest less in energy efficiency technologies (Gillingham and Palmer 2014). Except for few contributions (Allcott and Sweeney 2016; Allcott and Greenstone 2017), the empirical findings confirm that lack of relevant information leads to underinvestment in energy efficiency (Ward et al. 2011; Newell and Siikamäki 2014; Davis and Metcalf 2016; Houde 2018). Not only lack of information but also

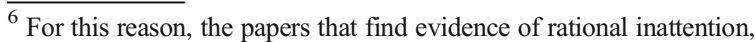
provide also evidence of myopia (Busse et al. 2013; Allcott and Wozny 2014).
} 
asymmetric information combined with opposing interests (also called split incentives) between a principal (for example, the landlord, who is responsible for the investment decision) and an agent (the tenant, who pays the energy bill) represents barriers to energy efficiency (Gillingham and Palmer 2014). It is difficult and expensive for the principal to verify what the agent is doing. An actor may be unconvinced about the energy-efficient attributes of a product or a house. Moreover, the principal and the agent can have conflicting goals, preferences, and incentives.

Given asymmetric information and split incentives, some robust conclusions can be reached. First, investment in profitable energy efficiency technologies depends on the ownership status of a house, with renters being less likely to invest in renovation or efficient appliances (Davis 2010; Gillingham et al. 2012; Phillips 2012; Krishnamurthy and Kristrom 2015). Mills and Schleich (2010) find that renting compared with owning the residence does not significantly influence the adoption of energy-saving compact fluorescent lamps. Second, the type of payment regime between the landlord and the tenant also influences energy efficiency investment. Myers (2015) finds that landlords in utilityincluded apartments are more likely to invest in conversion from inefficient oil heating to more efficient natural gas heating, compared with landlords who do not pay for energy. Energy efficiency is costly to observe, and prospective tenants may not be willing to pay higher rents for higher efficiency that they are not aware of. Papineau (2013) however finds that energy efficient yet unlabeled buildings, constructed under an energy code, are associated with significant rent and selling price premiums. This finding is consistent with little asymmetric information. Third, the type of payment regimes also impacts energy use. In particular, utility-included rents contribute to lower effort in energy conservation of tenants (Levinson and Niemann 2004; Maruejols and Young 2011; Elinder et al. 2017).

As a third external barrier to energy efficiency, Schleich et al. (2016) consider financial and technological risks. Technology performance for example, influences the profitability of an investment and the survival of a business, and this in turn affects adoption. Moreover, energy efficiency investments own a certain degree of risks because of the uncertainty related to the actual as compared with the expected energy savings. Risks are also connected to the fluctuations in fuel prices and to the irreversibility of the investment. Anderson and Newell (2004) confirm that firms fail to undertake profitable investments recommended after an energy audit because of risks, along with information barriers.

As in the case of the different behavioral anomalies, the distinction between external and internal barriers is often more theoretical than practical. In many circumstances, it is difficult to disentangle one barrier from the other. For example, lack of information can be the consequence of inattention or constraints in assessing available information. At the same time, it is classified as an external barrier to energy efficiency if it results from an effective discrepancy between the information available to the agents involved in a transaction. A study by Newell and Siikamäki (2014) is one of the few attempts to disentangle the effect of imperfect information from alternative explanations linked to consumer behavior, such as not constant discounting. The authors find that lack of relevant information is the most important constraint to cost-effective energy efficiency decisions. Additional research is needed to better disentangle behavioral effects from market failures in order to identify the most effective policy interventions.

\section{Literature review on policy interventions}

To overcome external and internal barriers, policies and interventions have been used. However, a substantial portion of the potential benefits of energy efficiency is still uncaptured, as the effectiveness of policies can be improved (Gillingham et al. 2009). Drawing from the existing literature, the objective of this section is to present the available policies and interventions and discuss their effectiveness in addressing both energy use and investment in energy efficiency technologies. ${ }^{7}$ Three types of policy instruments have been used: information-based instruments, regulatory instruments, and economic and financial programs (Gillingham et al., 2006).

\footnotetext{
$\overline{7}$ The studies included in this review were checked against a minimum standard of quality. For example, in those studies that make use of an experimental design, the control group was available, the treatment was randomly allocated and if not, selection bias was addressed using adequate instruments, such as matching techniques.
} 
Provision of information

Informational instruments are intended to influence consumers' behavior by disclosing crucial information about potential savings through, for example, energy audits and product labelling. Within this group of instruments are also included low-cost motivational and persuasion strategies also called "nudges" (Schultz et al. 2007; Goldstein et al. 2008). These are well-crafted interventions that provide feedback, peer comparisons, injunctive norms (Abrahamse et al. 2007), or interventions that manipulate the default setting and the information metrics. There are also programs that make consumers focusing on losses rather than gains or make consumers setting a goal. The design of this second type of interventions relies strongly on guidance from psychologists and behavioral scientists.

Some policies mainly address investment in energyefficient products. Table 1 presents the correspondence between the policy options and the domain they intend to influence, whether investment or energy use. Audits are tailored and highly personalized information and consist of recommendations for attic insulation; sealing of windows and doors; lighting, heating, and cooling improvements; and replacement of appliances. They can improve energy efficiency because homeowners may not be aware that their homes are inefficient and choose to follow some of the recommendations of the auditors. Frondel and Vance (2013) analyze the effect of home energy audits and find that, on average, audits increase energy efficiency investments in home renovations. Alberini and Towe (2015) find that participation in the home energy audit program reduces energy use. However, Allcott and Greenstone (2017) report that the benefits of auditing are inferior to the costs. Information on the private and social benefits of an investment that could follow-up a home energy audit did not influence the participation in the audit program. In this analysis, only price interventions, in the form of subsidies for the audit, increased the take-up of the program.

Energy labelling discloses energy-saving information of specific products. ${ }^{8}$ The impact of this type of intervention is not clear, and eventually depends on the empirical approach adopted for the analyses. While

\footnotetext{
${ }^{8}$ The US has adopted the Energy Star program; in Europe the Regulation (EU) 2017/1369 of the European Parliament provides a framework for energy labelling that repeals the Directive 2010/30/EU.
}

artefactual field experiments suggest that the provision of information improves energy-efficient choices (Ward et al., 2011; Allcott and Taubinsky, 2015; Houde, 2018), natural field experiments indicate that imperfect information and inattention are minimal barriers to energy efficiency and the provision of information is ineffective at increasing demand for energy-efficient products (Allcott and Taubinsky 2015; Allcott and Sweeney 2016). ${ }^{9}$ In Kallbekken et al. (2013), the combination of information at the point of purchase and a training treatment of sales staff leads consumers to purchasing more energy-efficient tumble driers but no effect on fridge-freezers sales. ${ }^{10}$ A major difference between the two approaches is that in natural field experiments, the (store) environment allows the control group to access information on the different energy efficiency technologies. The availability of this information to the control group may have reduced the effectiveness of the information treatment.

Camilleri and Larrick (2014) find that simply manipulating the metric (consumption of gas versus the cost of gas) and the scale (100 miles versus 15,000 miles versus 100,000 miles) on which fuel economy information is expressed, would shift preferences towards investment in more fuel-efficient vehicles. Ungemach et al. (2017) find that providing multiple translations of energy efficiency metrics could help guide consumer behavior.

Other information intervention is mainly directed to affect energy use. Heinzle (2012) assesses the importance of timeframe and format in which information about energy consumption is presented. The author concludes that framing information in terms of operating cost rather than physical measurement, such as "watts," is more effective in influencing consumer behavior but only if the information is presented over the lifetime of the product. Davis and Metcalf (2016) find that labels enhanced with local electricity costs information lead to more energy-efficient choices. Tailored energy labels produce larger gains than non-tailored ones. Newell and Siikamäki (2014) conclude that information content and label style strongly influence the valuation of water heaters. In particular, they compare various elements of information labels and find that the

\footnotetext{
$\overline{9}$ Artefactual field experiments are choice experiments and computerbased experiments, where behavior is observed in an artefactual environment. On the contrary, in natural field experiments, such as experiments conducted in stores, behavior is observed in naturally occurring environment. Allcott and Taubinsky (2015) apply both approaches.

${ }^{10}$ The authors use a non-random control group in their analysis.
} 
Table 1 Policy option and domain

\begin{tabular}{|c|c|c|}
\hline Policy option & Domain & Policy category \\
\hline Audits & Investments & Information program \\
\hline Commitment and goal setting programs & Energy use & Information program \\
\hline $\begin{array}{l}\text { Default option that favors energy conservation } \\
\text { to opt-out rather than opt-in }\end{array}$ & Energy use; investment & Information program \\
\hline Feedback & Energy use & Information program \\
\hline Labelling & Investments & Information program \\
\hline Loss-framed messages & Energy use & Information program \\
\hline Manipulation of timeframe and format of the information & Energy use & Information program \\
\hline Metrics and scales that match the problem-solving & Investments & Information program \\
\hline Moral suasion and appeal to intrinsic values & Energy use; investment & Information program \\
\hline Multiple translations of energy-efficiency metrics & Investments & Information program \\
\hline Peer comparison & Energy use & Information program \\
\hline Pricing programs characterized by lower spread of charges & Energy use & Information program \\
\hline Vivid signals such as thermal images & Energy use & Information program \\
\hline Energy performance certificates and building codes & Investments & Regulatory instruments \\
\hline Standards & Investments & Regulatory instruments \\
\hline Grants and loan facilities & Investments & Economic and financial instruments \\
\hline Guarantees on energy efficiency investments & Investments & Economic and financial instruments \\
\hline Rebates & Investments & Economic and financial instruments \\
\hline Subsidies & Investments & Economic and financial instruments \\
\hline Tax credits & Investments & Economic and financial instruments \\
\hline Tax deduction & Investments & Economic and financial instruments \\
\hline Energy taxes & Investments & Economic and financial instruments \\
\hline
\end{tabular}

economic value of energy saving is the most effective piece of information for energy-efficient decisions. Asensio and Delmas (2015) find that fear of the health consequences of energy use is strong a motivator of energy conservation and conclude that information on health externalities of electricity production outperforms monetary savings information.

Some information interventions aim at providing easily accessible feedback on the quantity of energy used through various technological means, such as inhome monitors, computers, mobile phones, and/or other portable displays. Meta-analyses on large number of rigorous studies have been used to assess if feedback works (Fischer 2008; McKerracher and Torriti 2013; Karlin et al. 2015; Bertoldi et al. 2016). The conclusion of these studies is that feedback has a positive effect on energy conservation. Interestingly, Goodhew et al. (2015) find that thermal images of heat losses in homes motivate households to reduce energy use and take energy-saving measures more than a carbon footprint audit. Thaler and Sunstein (2008) report that proving simple but vivid signal of energy consumption through light bulbs that change color at different energy prices are effective in reducing energy consumption.

Schultz et al. (2007), Ayres et al. (2012), and Costa and Kahn (2013) find that feedback programs that provide descriptive normative messages through peer comparison are successful in reducing residential energy use. However, Allcott and Rogers (2014) report that the effort in reducing electricity is not persistent and decays after some time. They document that after an initial reaction, consumers forget about the report and return to baseline consumption. However, this pattern of action and backsliding diminishes as the feedback program continues. These results are consistent with consumers being cued by the first reports but gradually investing in capital stock, which ensures long-run persistency of the effects. In this respect, the report acts by drawing attention to energy use. Allcott (2011b) as well confirms that consumers react to the report not because their knowledge increases, but because the report increases the moral cost of energy use. Even if peer 
comparison affects energy use, a meta-analysis of 30 different studies published between 1976 and 2013 concludes that peer comparison is less powerful than other social influence interventions, because it delivers the feedback in a fairly anonymous way (Abrahamse and Steg 2013). The most effective interventions are those where information is provided by block leaders, who are persons belonging to the same social network and make use of face-to-face interactions.

Harding and Hsiaw (2014) test the effect of commitment programs on energy use. They document that people voluntarily enroll in the goal program, setting personal conservation goals. The authors report substantial and persistent energy conservation among consumers who commit to realistic goals, but no savings among consumers who choose very low or unrealistically high goals. Becker (1978) as well finds that too easy goals to reduce electricity are not effective. On the contrary, individuals who had been given a relatively difficult goal in combination with a feedback performed better. Goal setting proves to be effective in particular in combination with tailored feedback (McCalley and Midden 2002; Abrahamse et al. 2007). The use of default setting that favors the environment is an important nudge to promote pro-environmental behavior. Pichert and Katsikopoulos (2008) find that people are more likely to choose a green source of energy if the green option is presented as the default. McCalley (2006) finds that removing the default temperature settings from washing machines brings to significant energy saving. Brown et al. (2013) report that manipulating the default settings on office thermostats reduces the chosen temperature.

The use of messages that focus on the costs of the less efficient behavior, namely loss-framed messages, rather than the benefits of the most efficient one, are used to influence energy use (Frederiks et al. 2015). Dütschke and Paetz (2013) find that consumers prefer pricing programs characterized by lower spread of charges, so that they can avoid the risk of too high bills. This finding has implications for energy tariff configurations.

Pelletier and Sharp (2008) highlight the importance of framing messages in terms of whether they serve intrinsic goals (i.e., health, well-being) rather than extrinsic goals (i.e., make or save money, comfort) in order to increase the level of self-determined motivation and thus induce pro-environmental behavior.
Regulatory instruments

Regulatory instruments define enforceable actions aimed at meeting specific environmental quality targets. Standards lead to a ban on certain classes of products which do not meet some efficiency standards. Energy performance certificates exclude from the renting market properties that do not meet minimum energy requirements. Building codes specify the minimum efficiency standards for buildings. Regulatory instruments have been mainly used in the investment domain as they are not designed to influence energy curtailment and they are found to expedite the transitions towards more energy-efficient investments (Greening et al. 1997; Davis 2008; de Melo and Jannuzzi 2010; Costa and Kahn 2010, 2011; Tao and Yu 2011; Aroonruengsawat et al. 2012; Jacobsen and Kotchen 2013; Mills and Schleich 2014).

However, Allcott and Taubinsky (2015) raise concerns about the use of standards. These instruments generate welfare losses due to fewer available choices and force behavioral change on those who gain little from energy efficiency. Concerns about the use of standards arise also in the context of fuel-economy. In the USA, higher CAFE standards are generally found to be inferior to gasoline taxes in improving energy efficiency. Austin and Dinan (2005) report that gasoline tax would accumulate savings much earlier than CAFE standards. A tax not only encourages the purchase of more fuelefficient vehicles, but it also discourages driving. Jacobsen (2013) confirms that gasoline taxes are more efficient than CAFE regulation. Moreover, examining both the new and used vehicle markets, the author finds that in the long run, fuel economy standards are more regressive than expected as they generate larger proportional welfare losses to low-income households. Fischer et al. (2007) conclude as well that the efficiency rationale for raising fuel economy standards is weak.

Ito and Sallee (2014) document that "attributebased" standards generate an additional distortion to the market. This type of policy is designed conditional on product attributes rather than the target they wish to achieve. ${ }^{11}$ Attribute-based policies tend to provide a less strict standard for products that are larger and more polluting, thus creating perverse incentives. The authors find that, as a consequence of weight-based standards, the Japanese car market has experienced an increase in

${ }^{11}$ The same problem applies to attribute-based tax and subsidies. 
vehicle weights, and this lowers fuel economy and increases externalities related to accidents.

To summarize, efficiency standards are an inferior instrument compared to other policies, such as information programs or taxes, as they do not influence behavior by discouraging the use of energy-using products. They also introduce some distortions, reducing the available choice and creating perverse incentives.

Economic and financial instruments

Economic and financial programs provide monetary incentives for energy efficiency such as grants and loan facilities, subsidies, tax deduction, tax credits, rebates, and guarantees. Energy taxes are also a financial instrument that contributes to energy efficiency by increasing the relative prices of less efficient products. Just like standards, product subsidies on efficient products or increased taxes on inefficient products impose a relative shadow cost on less efficient products (Allcott et al. 2014). This shadow cost means that consumers pay relatively less for more efficient products. Like regulatory instruments, they facilitate the investment in energy-efficient products, while they have no effect on behavior related to energy use. They are linked to the upfront investment costs while they do not reward any behavior change, related to energy use (Bertoldi et al. 2013).

Taxes should be preferable to standards, given that their cost is transparent, they promote behavioral changes, and they take into consideration the heterogeneity of consumers (Austin and Dinan 2005). Taxes have drawbacks as well. They produce negative distributional effects and their impact is limited if the price elasticity of energy demand is small (Jacobsen 2013). Wagner (2016) finds that environmental preferences shape the effectiveness of relative price and tax incentives, with environmentalists being less sensitive to changes in prices and taxes than their less environmental counterparts.

There are important concerns however with subsidies, tax deduction, tax credits, and rebates. First, these policy instruments are associated with a rebound effect (Sorrell et al. 2009; Alberini et al. 2016; Bertoldi 2017), whereby part of the potential savings are wiped out by changes in people's behavior. Second, they encourage free-riding (Houde and Aldy 2017). Third, they need to be financed through, for example, distortionary taxes and finally they are not always cost-effective
(Boomhower and Davis 2014; Datta and Gulati 2014; Davis et al. 2014). Moreover, a meta-analysis of 42 utility conservation programs in the residential, commercial, and industrial sectors found that actual energy-saving estimates for residential rebate programs are lower than engineering-economic estimates (Nadel and Keating 1991). It should be noted that the actual savings can be lower than the predicted ones, because the former may only consider the economic benefit of the intervention. On the contrary, energy-engineering models take into account not only the economic but also the "achievable" potentials. Finally, Allcott and Greenstone (2017) analyze the impact of an energy efficiency program, which subsidizes a home energy audit and subsequent recommended investments. They report a negative social welfare induced by the program. The benefit from reduced energy, which in their calculation includes also externalities induced by local air pollution, and greenhouse gases, does not compensate for the reduction in consumer utility, due to the higher taxes required to finance the program. However, they also conclude that the market for home energy audits and retrofits would almost entirely disappear in the absence of government intervention.

Meta-analyses can be used to compare the performance of information and non-information interventions. For example, Abrahamse et al. (2005) review 38 different articles dating from 1977 to 2004 and conclude that information programs increase knowledge but this does not necessarily translate into behavioral changes or energy savings. Monetary rewards are successful in engaging consumers in energy conservation, but the effect is not persistent in time. Commitment programs have long-term effects and are more effective when made in public rather than private. Finally, feedback reduces energy use in particular if it is provided frequently, through continuous electronic feedback for instance. Delmas et al. (2013) present the most comprehensive meta-analysis of different types of interventions. These include feedback, energy savings tips, energy audits, financial incentives, and peer comparisons. The meta-analysis shows an average energy use reduction of $7.4 \%$. Overall, they find that individualized audits and consulting ensure the highest energy savings and are comparatively more effective than strategies that provide historical, peer comparison energy feedback. This outcome may depend first on the fact that feedback proves to be effective if delivered in real time, and none of the studies in the meta-analysis considered real time 
peer comparisons. Second, social influence is maximized in face-to-face interactions (Abrahamse and Steg 2013), while the social comparison interventions in the meta-analysis are mainly anonymous.

Ito et al. (2015) compare the effects of appealing to intrinsic versus extrinsic motivations. The authors find that both moral suasion and economic incentives induce the desired conservative effects, but while the former exerts diminishing effects, the latter produces persistent effects, leading to habit formation. Appealing to economic rather than biospheric concerns not only could be ineffective in securing behavior change, but also counterproductive. Extrinsic rewards can sometimes crowd out intrinsic motivation to act pro-environmentally and consequently backfire and discourage the proenvironmental behavior they are meant to encourage (Schwartz et al. 2015).

\section{Discussion}

The main contribution of the present paper is to offer a correspondence between the different barriers, both internal and external, and the policy options available. Drawing from the literature surveyed in Section 3 on the effectiveness of the different policies, this section identifies which barrier the policy intends to overcome and combines policies with barriers.

First, the information instruments not only help to overcome information barriers, but also address many behavioral barriers to energy efficiency. A large number of interventions (energy audits, product labelling, energy performance certificates, and nudges) have been designed to address bounded rationality, because they end up guiding the consumers in the decision process, and consequently they lower the cognitive costs of energy decision-making. An important aspect that emerges from the literature review is that what matters is not only the content of the information program but also the way in which the information is presented. For example, the use of information metrics that match the problem-solving processes (for example, operating costs rather than the physical measurement) or providing multiple translations of energy efficiency metrics have the greatest influence on consumer preferences and choices. This is because the decision-making is less effortful if the problem representation matches the problem-solving processes (Heinzle 2012; Camilleri and Larrick 2014; Ungemach et al. 2017).
Because of bounded rationality, another result of this review is that vivid signals such as thermal images as well as interventions that make one recall energy-saving actions that are easily available in memories are effective because they provide information which is easy to process (Goodhew et al. 2015; Thaler and Sunstein 2008).

Feedbacks are as well designed to address bounded rationality, because they guide consumers in the decision-making process. Feedbacks can also address rational inattention because they should make consumers aware of their consumption and potential impacts. However, Jessoe and Rapson (2014) and Lynham et al. (2016) conclude that in-home-displays while help consumers improve the decision-making process in case of high prices, they are less likely to make prices more salient.

Feedback programs that provide descriptive normative messages through peer comparison encourage energy conservation because they evoke social comparison but also because they make salient a social norm in favor of energy conservation. Social norms can effectively induce behavioral change (Schultz et al. 2007). Conforming to social norms is sometimes a mental shortcut that people use to address complexity in decision-making. For this reason, descriptive normative messages can address bounded rationality.

As outlined in Section 2, many other behavioral barriers to energy efficiency exist. To address reference-dependent preferences, commitment and goal setting programs have been introduced (McCalley and Midden 2002; Abrahamse et al. 2007). Goal setting entails giving consumers a specific reference point, for instance, to save energy by a certain amount. A similar strategy is commitment, whereby people make a pledge or promise to engage in sustainable energy behavior. This program should reduce impulsivity and encourage investments that have immediate and larger costs but delayed rewards. In general, commitment and goal setting programs attract present-biased consumers and consumers with limited self-control. These consumers are aware of their need for a commitment to behave proenvironmentally. With no commitment, they will consume more electricity than ex ante preferred. Goal setting programs, which offer a menu of energy savings options with respect to annual electricity savings, however, are effective only if consumers commit to realistic goals (Harding and Hsiaw 2014; Becker 1978), which should not be too easy (Becker 1978). 
Interventions, that set the default option in favor of the environment (such as participation in proenvironmental programs as an opt-out rather than an opt-in, or default temperature for heating or washing at low degrees) are able to address the status quo bias (Pichert and Katsikopoulos 2008, McCalley 2006; Brown et al. 2013) because people tend to stick to the status quo (Kahneman et al. 1991).

The use of loss-framed (rather than gain-framed messages) addresses loss-aversion, reference-dependence, and non-linear probability weighting, because this manipulation makes the loss more salient, memorable, and motivating (Frederiks et al. 2015).

To address environmental preferences, the way the message is framed proves to be extremely important. Information programs, even if they are designed to increase knowledge and awareness in general, tend to encourage behavioral change among people who strongly endorse biospheric (environmental) values. Information is effective when it resonates with people's central values (Steg et al. 2015). Targeted policy interventions that frame messages in terms of intrinsic goals, moral suasion, and appeal to intrinsic values are therefore crucial in this context. Given that informational interventions are perhaps ineffective in those who care less about the environment, they should be directed towards those who strongly care about the environment. This is because they make consumers more inclined to act on their values. Taufik et al. (2016) find that the intention to act proenvironmentally is largely driven by the positive feeling about acting pro-environmentally and less so by the perceived benefits connected to this action. Therefore, to induce pro-environmental behavior, information campaigns should stress the selfless, societal aspects of acting pro-environmentally and should resonate with people's feelings, instead of exclusively appealing to their calculations.

The second set of programs, called regulatory instruments, include energy efficiency standards, building codes and minimum energy performance certificates. By removing energy-inefficient products/properties from the market, they are designed to address inattention to operating costs and to energy savings connected to energy-efficient products. They also address misperceptions of energy costs due to bounded rationality and also present bias, in particular lack of self-control and temptation. Moreover, they are also justified by the presence of imperfect information.
Allcott and Taubinsky (2015) find that imperfect information and rational inattention alone cannot justify a ban on incandescent lightbulbs. Standards are only a second-best policy compared to information disclosure programs. The latter directly address information asymmetries and rational inattention without reducing the available choices. A ban on incandescent lightbulbs produces welfare losses to consumers who strongly prefer these inefficient lightbulbs even after being informed of the apparently large cost savings. In the paper, these welfare losses outweigh the gains to uninformed or inattentive consumers. On the contrary, Tsvetanov and Segerson (2014) acknowledge that stricter standards on top-freezer refrigerators could make some consumers worse off, but they find that these instruments are on average welfare improving under a self-control framework, where individuals are characterized by temptation. The authors conclude that it is extremely important to identify the underlying behavioral assumption used in evaluating the welfare effects of energy efficiency standards.

In the context of fuel economy, the inefficiency of standards is confirmed even in the presence of some behavioral anomalies. Parry et al. (2014) compare the welfare effects of energy efficiency standards and pricing policies in the case of misperceptions of energy costs due to rational inattention or bounded rationality. They conclude that even with large misperceptions, an optimal policy portfolio should make only a limited use of fuel economy and power sector efficiency standards. Pricing policies should be the first best option, while efficiency standards can play a role only if practical constraints on gasoline/electricity taxes arise.

As far as the third type of programs, called economic and financial instruments, such as grant and loan facilities, subsidies, tax deduction, tax credits, rebates, guarantees, and energy taxes, some conclusions can be drawn. Except for higher taxes, economic incentives address capital market failures. Moreover, Blumstein (2010) reports that some individuals choose to make energy efficiency investments because their awareness has been raised by the existence of the incentive schemes. In this respect, economic incentives may address an information problem. Economic incentives are also particularly relevant for persons who are risk averse because they lower the upfront costs of an investment. Finally, subsidies and taxes can address the same type of barriers as standards, in particular rational 
inattention, bounded rationality, and present bias. This is because, in case of these behavioral barriers, product subsidies and taxes can divert purchases towards the most efficient appliances.

If there are no behavioral anomalies, the social optimum is to apply a Pigouvian tax or equivalent instruments (Gillingham and Palmer 2014). For example, Galarraga et al. (2016) find that in Spain, a tax scheme on dishwashers, refrigerators, and washing ensures greater energy savings than a subsidy scheme. In the presence of behavioral anomalies, however, subsidies for energy efficiency investments represent the optimal policy option. Hassett and Metcalf (1995) report that subsidies are much more effective than an equivalent tax in particular in the presence of loss aversion and reference dependence. People strongly prefer avoiding losses to achieving gains, and a subsidy tends to reduce the loss (represented by the cost of the investment) rather than increase the gains (because of lower operating costs due to lower use). Allcott and Taubinsky (2015) as well report that a moderate subsidy could be optimal to increase the market for compact fluorescent lightbulbs in case of imperfect information and inattention. Allcott et al. (2014) report that, if consumers undervalue energy costs because of rational inattention or imperfect information, the optimal combination of tax and subsidy implies a quite large product subsidy. A subsidy is more effective than a tax in targeting the most biased consumer, because consumers who undervalue energy costs the most are also the least sensitive to the energy tax.

As a general rule, targeting the corrective measures to the different groups of consumers is crucial to achieving the highest energy conservation. From a welfare perspective, what matters is whether the consumers affected by the distortions are also affected by the policy interventions. If, from an institutional point of view, the eligibility of subsidies cannot be restricted to a specific group, targeted marketing at the groups most affected by the distortion could produce large gains (Allcott et al. 2015).

Finally, the use of guarantees, whereby governments or energy providers share the costs and risks but also the benefits from future savings related to energy-efficient renovations, can improve energy efficiency by reducing the perceived risk of the investment (Fischbacher et al. 2015). For this reason, guarantees can address risk preferences as well as problems related to financial and technological risks. A summary of all these results is presented in Table 2.

\section{Summary and conclusions}

Various barriers to the adoption of energy efficiency technologies have been identified and different instruments have been introduced to address the barriers. By assessing the effectiveness of the different types of policies against the barriers they aim to address, this paper is able to provide some conclusions.

First, feedback is an effective way to influence behavior related to energy use, in particular if the feedback is combined with a goal intervention (McCalley and Midden 2002). Feedback that provides peer comparison on energy use encourages energy conservation. There are other social influence approaches, such as interventions where the information is provided by block leaders that prove to be effective because they deliver the feedback less anonymously. The medium through which the feedback is offered can as well influence behavior, with feedback that uses the most engaging and interactive medium (such as a computer) being the most effective. This opens up to the possibility that further development of IT applications, social media, and cellphone messaging will ensure larger improvements in energy efficiency in the future.

Second, audits improve energy efficiency because they increase awareness of possible improvements. The realization of energy efficiency gains however crucially depends on an effective follow-up action.

Third, not only the content but also the way in which the information is presented proves to be important, with the timeframe, format, and metrics being strong moderators of the effectiveness of this type of interventions. Information campaign should make use of multiple translations of energy efficiency metrics or information metrics that match the problem-solving processes in order to simplify the decision-making process.

As far as product labelling, the evidence is mixed and depends on the methodology used for the analysis. More research is needed to fully understand if labelling really improves energy-efficient choices.

Fourth, standards, information programs, subsidies, and taxes are directed to the same types of external barriers. However, standards are an inferior instrument compared to the other interventions because they do not influence behavior by reducing the use of energy-using 
products and generate a welfare loss by limiting the available choices. Information programs, subsidies, and taxes represent a more direct and efficient response to the targeted external barriers.

Another crucial point emerging from this review is the importance of targeting the policies. For example, policies should target investments that are less conspicuous in place of those that confer a status benefit. People in search of social approval are willing to invest in the latter without any policy intervention. Moreover, while some interventions are ineffective among those who care less about the environment, they could still deliver substantial benefits if targeted towards those who strongly care about the environment. This is because they make them more inclined to act on their values. Unfortunately, an effective targeting is a difficult task. Those who will most benefit from the intervention needs to be correctly identified and effectively reached. This implies a successful inclusion of the target population and exclusion of the non-target population. Moreover, in some circumstances, there are restrictions in the possibility to target a policy. For example, subsidies cannot be restricted to a specific group. In this case, one can think of targeting a marketing campaign. The campaign can target the consumers that are mostly affected by the distortion that the subsidy aims to address.

The complexity and variety of barriers pertaining to individual behavior call for increasing insights from behavioral economics. There is a variety of barriers that pertain to individual behavior that cannot be addressed using economic and regulatory instruments. Moreover, economic and regulatory instruments fall short in cases of behavioral barriers such as status quo bias, bounded rationality, or among those with reference dependent preferences or with strong environmental preferences. For example, energy taxes, such as gasoline taxes, are a good solution because they are transparent, promote behavioral changes, and take into consideration the heterogeneity of consumers but they give rise to negative distributional effects. In case of reference dependence, subsidies and tax credits are better than taxes, but subsidies produce a rebound effect, encourage free riding, and need a source of financing. Extrinsic rewards can sometimes crowd out intrinsic motivation to act proenvironmentally and consequently backfire and discourage the pro-environmental behavior they are meant to encourage. Ad hoc solutions, such as default options that favor energy conservation, loss-framed messages, vivid

Table 2 Policy options to address the specific barrier to energy efficiency

\begin{tabular}{|c|c|}
\hline Barriers & Policy option \\
\hline Time preferences & Commitment and goal setting programs \\
\hline Risk preferences & Grants and loan facilities, subsidies, tax deduction, tax credits, rebates, guarantees \\
\hline Environmental preferences & Messages framed in terms of intrinsic goals, moral suasion, and appeal to intrinsic values \\
\hline $\begin{array}{l}\text { Reference-dependent preference and } \\
\text { non-linear probability weighting }\end{array}$ & $\begin{array}{l}\text { Loss-framed messages, commitment and goal setting programs, pricing programs } \\
\text { characterized by lower spread of charges, subsidies, tax credits }\end{array}$ \\
\hline Bounded rationality & $\begin{array}{l}\text { Energy audits, product labelling, feedback, vivid signals such as thermal images, peer } \\
\text { comparison, information metrics and scales that match the problem-solving, } \\
\text { manipulation of timeframe and format of the information, multiple translations of } \\
\text { energy-efficiency metrics, standards, energy performance certificates, building codes, } \\
\text { subsidies, tax credits, rebates, loans, taxes }\end{array}$ \\
\hline Rational inattention & $\begin{array}{l}\text { Feedback, standards, energy performance certificates, building codes, subsidies, tax credits, } \\
\text { rebates, loans, taxes }\end{array}$ \\
\hline Present bias and myopia & $\begin{array}{l}\text { Commitment and goal setting programs, standards, energy performance certificates, } \\
\text { building codes, subsidies, tax credits, rebates, loans, taxes }\end{array}$ \\
\hline Status quo bias & Set the default option that favors energy conservation to opt-out rather than opt-in \\
\hline Capital market failures & Grants and loan facilities, subsidies, tax deduction, tax credits, rebates, guarantees \\
\hline Information problems & $\begin{array}{l}\text { Energy audits, product labelling, feedback, standards, energy performance certificates, } \\
\text { building codes, grants and loan facilities, subsidies, tax deduction, tax credits, rebates, } \\
\text { guarantees }\end{array}$ \\
\hline Financial and technological risks & Guarantees on energy efficiency investments \\
\hline
\end{tabular}


information such as thermal images of heat losses and messages framed in terms of intrinsic goals and moral suasion are more effective in addressing the relevant barrier and motivate households to reduce energy use.

Another limitation of economic and regulatory instruments is that they mainly influence behavior in the investment domain. A large portion of energy saving can be achieved through behavior related to energy use.

This analysis focuses principally on the residential sector. The findings from the study of households do not necessarily translate into the business and manufacturing world where decision-making mechanisms, information flows, resources, and incentives can be quite distinct. A priority for future research is an analysis of the conduct of industrial, commercial firms, government agencies, and other non-profits organizations, which account for a great share of energy use and have large potentials for emission reductions. To date, because of little available data, and concerns of generalizing across a population of organizations that varies in size, function, scope, and interest in emission reduction (Stern et al. 2016), the empirical evidence is scarce.

Acknowledgements I am very thankful to Elena Verdolini, Ellen van der Werff, Linda Steg, and seminar participants at IAEE international conference for helpful comments and suggestions. I would like to thank the anonymous referees for their constructive comments.

Funding Information This works has received funding from the European Union's Horizon 2020 research and innovation program under the project PENNY - psychological social and financial barriers to energy efficiency, grant agreement no. 723791.

\section{Compliance with ethical standards}

Conflict of interest The author declares that she has no conflict of interest.

Open Access This article is distributed under the terms of the Creative Commons Attribution 4.0 International License (http:// creativecommons.org/licenses/by/4.0/), which permits unrestricted use, distribution, and reproduction in any medium, provided you give appropriate credit to the original author(s) and the source, provide a link to the Creative Commons license, and indicate if changes were made.

Publisher's note Springer Nature remains neutral with regard to jurisdictional claims in published maps and institutional affiliations.

\section{References}

Abrahamse, W., \& Steg, L. (2013). Social influence approaches to encourage resource conservation: a meta-analysis. Global Environmental Change, 23(6), 1773-1785.

Abrahamse, W., Steg, L., Vlek, C., \& Rothengatter, T. (2005). A review of intervention studies aimed at household energy conservation. Journal of Environmental Psychology, 25(3), 273-291.

Abrahamse, W., Steg, L., Vlek, C., \& Rothengatter, T. (2007). The effect of tailored information, goal setting, and tailored feedback on household energy use, energy-related behaviors, and behavioral antecedents. Journal of Environmental Psychology, 27(4), 265-276.

Alberini, A., \& Towe, C. (2015). Information verus energy efficiency incentives: evidence from residential electricity consumption in maryland. Energy Economics, Frontiers in the Economics of Energy Efficiency, 52(Supplement 1), S30S40.

Alberini, A., Banfi, S., \& Ramseier, C. (2013). Energy efficiency investments in the home: Swiss homeowners and expectations about future energy prices. Energy Journal, 34(1), 4986.

Alberini, A., Gans, W., \& Towe, C. (2016). Free riding, upsizing, and energy efficiency incentives in Maryland homes. The Energy Journal, 37(1), 259-290.

Allcott, H. (2011a). Consumers' perceptions and misperceptions of energy costs. American Economic Review, 101(3), 98104.

Allcott, H. (2011b). Social norms and energy conservation. Journal of Public Economics, Special Issue: The Role of Firms in Tax Systems, 95(9-10), 1082-1095.

Allcott, H, Greenstone, M. (2017). Measuring the welfare effects of residential energy efficiency programs. SSRN Scholarly Paper ID 2945603.

Allcott, H., \& Rogers, T. (2014). The short-run and long-run effects of behavioral interventions: experimental evidence from energy conservation. American Economic Review, 104(10), 3003-3037.

Allcott, H., \& Sweeney, R. L. (2016). The role of sales agents in information disclosure: evidence from a field experiment. Management Science, 63(1), 21-39.

Allcott, H., \& Taubinsky, D. (2015). Evaluating behaviorally motivated policy: experimental evidence from the lightbulb market. American Economic Review, 105(8), 2501-2538.

Allcott, H., \& Wozny, N. (2014). Gasoline prices, fuel economy, and the energy paradox. Review of Economics and Statistics, 96(5), 779-795.

Allcott, H., Mullainathan, S., \& Taubinsky, D. (2014). Energy policy with externalities and internalities. Journal of Public Economics, 112, 72-88.

Allcott, H., Knittel, C., \& Taubinsky, D. (2015). Tagging and targeting of energy efficiency subsidies. American Economic Review, 105(5), 187-191.

Anderson, S. T., \& Newell, R. G. (2004). Information programs for technology adoption: the case of energy-efficiency audits. Resource and Energy Economics, 26(1), 27-50.

Aroonruengsawat, A., Auffhammer, M., \& Sanstad, A. H. (2012). The impacts of state level building codes on residential electricity consumption. Energy Journal, 33(1), 31-52. 
Asensio, O. I., \& Delmas, M. A. (2015). Nonprice incentives and energy conservation. Proceedings of the National Academy of Sciences, 112(6), E510-E515.

Austin, D., \& Dinan, T. (2005). Clearing the air: the costs and consequences of higher CAFE standards and increased gasoline taxes. Journal of Environmental Economics and Management, 50(3), 562-582.

Ayres, I., Raseman, S., \& Shih, A. (2012). Evidence from two large field experiments that peer comparison feedback can reduce residential energy usage. Journal of Law, Economics, and Organization, 29(5), 992-1022.

Becker, L. J. (1978). Joint effect of feedback and goal setting on performance: a field study of residential energy conservation. Journal of Applied Psychology, 63(4), 428-433.

Bertoldi, P. (2017). Are current policies promoting a change in behaviour, conservation and sufficiency? In An analysis of existing policies and recommendations for new and effective policies. ECEEE Summer Study Proceeding.

Bertoldi, P., Rezessy, S., \& Oikonomou, V. (2013). Rewarding energy savings rather than energy efficiency: exploring the concept of a feed-in tariff for energy savings. Energy Policy, 56, 526-535.

Bertoldi, P., Serrenho, T., Zangheri, P. (2016). Consumer feedback systems: how much energy saving will they deliver and for how long? ACEEE Summer Study on Energy Efficiency in Building.

Blumstein, C. (2010). Program evaluation and incentives for administrators of energy-efficiency programs: can evaluation solve the principal/agent problem? Energy Policy, 38(10), 6232-6239.

Bollinger, B., \& Gillingham, K. (2012). Peer effects in the diffusion of solar photovoltaic panels. Marketing Science, 31(6), 900-912.

Boomhower, J., \& Davis, L. W. (2014). A credible approach for measuring inframarginal participation in energy efficiency programs. Journal of Public Economics, 113, 67-79.

Bradford, D., Courtemanche, C., Heutel, G., McAlvanah, P., Ruhm, C. (2014). Time preferences and consumer behavior. In NBER working paper 20320. National Bureau of Economic Research.

Brennan, T. J. (2007). Consumer preference not to choose: methodological and policy implications. Energy Policy, 35(3), 1616-1627.

Brown, Z., Johnstone, N., Haščič, I., Vong, L., \& Barascud, F. (2013). Testing the effect of defaults on the thermostat settings of OECD employees. Energy Economics, 39, 128-134.

Bruderer Enzler, H., Diekmann, A., \& Meyer, R. (2014). Subjective discount rates in the general population and their predictive power for energy saving behavior. Energy Policy, 65, 524-540.

Busse, M. R., Knittel, C. R., \& Zettelmeyer, F. (2013). Are consumers myopic? Evidence from new and used car purchases. American Economic Review, 103(1), 220-256.

Camilleri, A. R., \& Larrick, R. P. (2014). Metric and scale design as choice architecture tools. Journal of Public Policy \& Marketing, 33(1), 108-125.

Cohen, F., Glachant, M., \& Söderberg, M. (2017). Consumer myopia, imperfect competition and the energy efficiency gap: evidence from the UK refrigerator market. European Economic Review, 93(April), 1-23.
Costa, D. L., \& Kahn, M. E. (2010. Energy conservation. NBER working paper 15939. National Bureau of Economic Research.

Costa, D. L., \& Kahn, M. E. (2011). Electricity consumption and durable housing: understanding cohort effects. American Economic Review, 101(3), 88-92.

Costa, D. L., \& Kahn, M. E. (2013). Energy conservation 'nudges' and environmentalist ideology: evidence from a randomized residential electricity field experiment. Journal of the European Economic Association, 11(3), 680-702.

Datta, S., \& Gulati, S. (2014). Utility rebates for ENERGY STAR appliances: are they effective? Journal of Environmental Economics and Management, 68(3), 480-506.

Davis, L. W. (2008). Durable goods and residential demand for energy and water: evidence from a field trial. The Rand Journal of Economics, 39(2), 530-546.

Davis, L. W. (2010). Evaluating the slow adoption of energy efficient investments: are renters less likely to have energy efficient appliances? NBER working paper 16114. National Bureau of Economic Research.

Davis, L. W., \& Metcalf, G. E. (2016). Does better information Lead to better choices? Evidence from energy-efficiency labels. Journal of the Association of Environmental and Resource Economists, 3(3), 589-625.

Davis, L. W., Fuchs, A., \& Gertler, P. (2014). Cash for coolers: evaluating a large-scale appliance replacement program in Mexico. American Economic Journal: Economic Policy, 6(4), 207-238.

de Groot, J., \& Steg, L. (2008). Value orientations to explain beliefs related to environmental significant behavior: how to measure egoistic, altruistic, and biospheric value orientations. Environment and Behavior, 40(3), 330-354.

de Melo, C., \& Jannuzzi, G. (2010). Energy efficiency standards for refrigerators in Brazil: a methodology for impact evaluation. Energy Policy, 38(11), 6545-6550.

Delmas, M. A., Fischlein, M., \& Asensio, O. I. (2013). Information strategies and energy conservation behavior: a meta-analysis of experimental studies from 1975 to 2012. Energy Policy, 61, 729-739.

Di Maria, C., Ferreira, S., \& Lazarova, E. (2010). Shedding light on the light bulb puzzle: the role of attitudes and perceptions in the adoption of energy efficient light bulbs. Scottish Journal of Political Economy, 57(1), 48-67.

Dunlap, R.E., Grieneeks, J.K., Rokeach, M. (1983). Human values and pro-environmental behavior. In In energy and material resources: attitudes, values, and public policy. Boulder, CO: West view.

Dütschke, E., \& Paetz, A.-G. (2013). Dynamic electricity pricing - which programs do consumers prefer? Energy Policy, 59, 226-234.

Ek, K., \& Söderholm, P. (2010). The devil is in the details: household electricity saving behavior and the role of information. Energy Policy, 38(3), 1578-1587.

Elinder, M., Escobar, S., \& Petré, I. (2017). Consequences of a price incentive on free riding and electric energy consumption. Proceedings of the National Academy of Sciences, 114(12), 3091-3096.

Erdem, C., Șentürk, İ., \& Șimșek, T. (2010). Identifying the factors affecting the willingness to pay for fuel-efficient vehicles in Turkey: a case of hybrids. Energy Policy, 38(6), 3038-3043. 
Hirst, E., \& Brown, M. (1990). Closing the efficiency gap: barriers to improving energy efficiency. Conservation and Recycling, 3, 267-281.

Farsi, M. (2010). Risk aversion and willingness to pay for energy efficient systems in rental apartments. Energy Policy, 38(6), 3078-3088.

Fischbacher, U., Schudy, S., Teyssier, S. (2015). Heterogeneous preferences and investments in energy saving measures. Munich Discussion Paper No. 2015-11.

Fischer, C. (2008). Feedback on household electricity consumption: a tool for saving energy? Energy Efficiency, 1(1), 79104.

Fischer, C., Harrington, W., \& Parry, I. W. H. (2007). Should automobile fuel economy standards be tightened? Energy Journal, 28(4), 1-29.

Frederick, S., Loewenstein, G., \& O’Donoghue, T. (2002). Time discounting and time preference: a critical review. Journal of Economic Literature, 40(2), 351-401.

Frederiks, E. R., Stenner, K., \& Hobman, E. V. (2015). Household energy use: applying behavioural economics to understand consumer decision-making and behaviour. Renewable and Sustainable Energy Reviews, 41, 1385-1394.

Frondel, M., \& Vance, C. (2013). Heterogeneity in the effect of home energy audits: theory and evidence. Environmental and Resource Economics, 55(3), 407-418.

Galarraga, I., Abadie, L. M., \& Kallbekken, S. (2016). Designing incentive schemes for promoting energy-efficient appliances: a new methodology and a case study for Spain. Energy Policy, 90, 24-36.

Gerarden, T., Newell, R. G., \& Stavins, R. N. (2015). Deconstructing the energy-efficiency gap: conceptual frameworks and evidence. American Economic Review, 105(5), 183-186.

Gerarden, T. D., Newell, R. G., \& Stavins, R. N. (2017). Assessing the energy-efficiency gap. Journal of Economic Literature, 55(4), 1486-1525.

Gigerenzer, G., \& Gaissmaier, W. (2011). Heuristic decision making. Annual Review of Psychology, 62, 451-482.

Gillingham, K., \& Palmer, K. (2014). Bridging the energy efficiency gap: policy insights from economic theory and empirical evidence. Review of Environmental Economics and Policy, 8(1), 18-38.

Gillingham, K., Newell, R. G., \& Palmer, K. (2006). Energy efficiency policies: a retrospective examination. Annual Review of Environment and Resources, 31, 161-192.

Gillingham, K., Newell, R. G., \& Palmer, K. (2009). Energy efficiency economics and policy. Annual Review of Resource Economics, 1(1), 597-620.

Gillingham, K., Harding, M., \& Rapson, D. (2012). Split incentives in residential energy consumption. The Energy Journal, 33(2), 37-62.

Goldstein, N. J., Cialdini, R. B., \& Griskevicius, V. (2008). A room with a viewpoint: using social norms to motivate environmental conservation in hotels. Journal of Consumer Research, 35(3), 472-482.

Goodhew, J., Pahl, S., Auburn, T., \& Goodhew, S. (2015). Making heat visible: promoting energy conservation behaviors through thermal imaging. Environment and Behavior, 47(10), 1059-1088.

Greening, L. A., Sanstad, A. H., \& McMahon, J. E. (1997). Effects of appliance standards on product price and attributes: an hedonic pricing model. Journal of Regulatory Economics, 11(2), 181-194.

Griskevicius, V., Tybur, J. M., \& Van den Bergh, B. (2010). Going green to be seen: status, reputation, and conspicuous conservation. Journal of Personality and Social Psychology, 98(3), 392-404.

Harding, M., \& Hsiaw, A. (2014). Goal setting and energy conservation. Journal of Economic Behavior \& Organization, 107(Part A), 209-227.

Harding, M., \& Rapson, D. (2017). Do voluntary carbon offsets induce energy rebound? A conservationist's dilemma. Mimeo University California Davis.

Hassett, K. A., \& Metcalf, G. E. (1995). Energy tax credits and residential conservation investment: evidence from panel data. Journal of Public Economics, 57(2), 201-217.

Heinzle, S. L. (2012). Disclosure of energy operating cost information: a silver bullet for overcoming the energy-efficiency gap? Journal of Consumer Policy, 35(1), 43-64.

Hobman, E. V., Frederiks, E. R., Stenner, K., \& Meikle, S. (2016). Uptake and usage of cost-reflective electricity pricing: insights from psychology and behavioural economics. Renewable and Sustainable Energy Reviews, 57, 455-467.

Houde, S. (2018). How consumers respond to product certification and the value of energy information. RAND Journal of Economics, 49(2), 453-477.

Houde, S., \& Aldy, J. E. (2017). Consumers' response to state energy efficient appliance rebate programs. American Economic Journal: Economic Policy, 9(4), 227-255.

Ito, K., \& Sallee, J.M. (2014). The economics of attribute-based regulation: theory and evidence from fuel-economy standards. NBER working paper 20500. National Bureau of Economic Research.

Ito, K., Ida, T., Tanaka, M. (2015). The persistence of moral suasion and economic incentives: field experimental evidence from energy demand. NBER working paper 20910. National Bureau of Economic Research.

Jacobsen, M. R. (2013). Evaluating US fuel economy standards in a model with producer and household heterogeneity. American Economic Journal: Economic Policy, 5(2), 148187.

Jacobsen, G. D., \& Kotchen, M. J. (2013). Are building codes effective at saving energy? Evidence from residential billing data in Florida. The Review of Economics and Statistics, 95(1), 34-49.

Jaffe, A. B., \& Stavins, R. N. (1994). The energy-efficiency gap what does it mean? Energy Policy, 22(10), 804-810.

Jessoe, K., \& Rapson, D. (2014). Knowledge is (less) power: experimental evidence from residential energy use. American Economic Review, 104(4), 1417-1438.

Kahn, M. E. (2007). Do greens drive hummers or hybrids? Environmental ideology as a determinant of consumer choice. Journal of Environmental Economics and Management, 54(2), 129-145.

Kahneman, D., \& Tversky, A. (1979). Prospect theory: an analysis of decision under risk. Econometrica: Journal of the Econometric Society, 263-291.

Kahneman, D., Knetsch, J. L., \& Thaler, R. H. (1991). Anomalies: the endowment effect, loss aversion, and status quo bias. The Journal of Economic Perspectives, 5(1), 193-206.

Kallbekken, S., Sælen, H., \& Hermansen, E. A. T. (2013). Bridging the energy efficiency gap: a field experiment on 
lifetime energy costs and household appliances. Journal of Consumer Policy, 36(1), 1-16.

Karlin, B., Zinger, J. F., \& Ford, R. (2015). The effects of feedback on energy conservation: a meta-analysis. Psychological Bulletin, 141(6), 1205-1227.

Köszegi, B., \& Rabin, M. (2006). A model of reference-dependent preferences. The Quarterly Journal of Economics, 121(4), $1133-1165$.

Kotchen, M. J., \& Moore, M. R. (2007). Private provision of environmental public goods: household participation in green-electricity programs. Journal of Environmental Economics and Management, 53(1), 1-16.

Kotchen, M. J., \& Moore, M. R. (2008). Conservation: from voluntary restraint to a voluntary price premium. Environmental and Resource Economics, 40(2), 195-215.

Krishnamurthy, C. K. B., \& Kristrom, B. (2015). How large is the owner-renter divide in energy efficient technology? Evidence from an OECD cross-section. The Energy Journal, 36(4), 85-104.

Laibson, D. (1997). Golden eggs and hyperbolic discounting. The Quarterly Journal of Economics, 112(2), 443-478.

Laibson, D., \& List, J. (2015). Principles of (behavioral) economics. American Economic Review, 105(5), 385-390.

Lange, I., Moro, M., \& Traynor, L. (2014). Green hypocrisy?: Environmental attitudes and residential space heating expenditure. Ecological Economics, 107, 76-83.

Levinson, A., \& Niemann, S. (2004). Energy use by apartment tenants when landlords pay for utilities. Resource and Energy Economics, 26(1), 51-75.

Liebermann, Y., \& Ungar, M. (1997). Life cycle cost: an individual consumer's perspective. Managerial and Decision Economics, 18(3), 227-234.

Liebermann, Y., \& Ungar, M. (2002). Efficiency of consumer intertemporal choice under life cycle cost conditions. Journal of Economic Psychology, 23(6), 729-748.

Lynham, J., Nitta, K., Saijo, T., \& Tarui, N. (2016). Why does realtime information reduce energy consumption? Energy Economics, 54, 173-181.

Macey, S. M., \& Brown, M. A. (1983). Residential energy conservation: the role of past experience in repetitive household behavior. Environment and Behavior, 15(3), 123-141.

Maruejols, L., \& Young, D. (2011). Split incentives and energy efficiency in Canadian multi-family dwellings. Energy Policy, 39(6), 3655-3668.

McCalley, L. T. (2006). From motivation and cognition theories to everyday applications and back again: the case of productintegrated information and feedback. Energy Policy, 34(2), 129-137.

McCalley, L. T., \& Midden, C. J. H. (2002). Energy conservation through product-integrated feedback: the roles of goal-setting and social orientation. Journal of Economic Psychology, 23(5), 589-603.

McKerracher, C., \& Torriti, J. (2013). Energy consumption feedback in perspective: integrating Australian data to metaanalyses on in-home displays. Energy Efficiency, 6(2), $387-405$.

Mills, B. F., \& Schleich, J. (2010). Why don't households see the light?: Explaining the diffusion of compact fluorescent lamps. Resource and Energy Economics, 32(3), 363-378.

Mills, B., \& Schleich, J. (2014). Household transitions to energy efficient lighting. Energy Economics, 46, 151-160.
Myers, E. (2015. Asymmetric information in residential rental markets: implications for the energy efficiency gap. Energy Institute at Haas Working Paper 246.

Nadel, S., \& Keating, K. (1991). Engineering estimates vs. impact evaluation results: how do they compare and why? Research Report U915. American Council for an Energy-Efficient Economy.

Newell, R. G., \& Siikamäki, J. (2014). Nudging energy efficiency behavior: the role of information labels. Journal of the Association of Environmental and Resource Economists, 1(4), 555-598.

Newell, R. G., \& Siikamäki, J. (2015). Individual time preferences and energy efficiency. American Economic Review, 105(5), 196-200.

Palmer, K. L., Walls, M. A., Gerarden, T. (2012). Borrowing to save energy: an assessment of energy-efficiency financing programs. Resources for the Future Report.

Papineau, M. (2013). Energy codes and the landlord-tenant problem. Carleton economic papers, CEP 15-03. Carleton University.

Parry, I. W. H., Evans, D., \& Oates, W. E. (2014). Are energy efficiency standards justified? Journal of Environmental Economics and Management, 67(2), 104-125.

Pelletier, L. G., \& Sharp, E. (2008). Persuasive communication and proenvironmental behaviours: How message tailoring and message framing can improve the integration of behaviours through self-determined motivation. Canadian Psychology/Psychologie Canadienne, 49(3), 210-217.

Phillips, Y. (2012). Landlords versus tenants: information asymmetry and mismatched preferences for home energy efficiency. Energy Policy, 45, 112-121.

Pichert, D., \& Katsikopoulos, K. V. (2008). Green defaults: information presentation and pro-environmental behaviour. Journal of Environmental Psychology, 28(1), 63-73.

Qiu, Y., Colson, G., \& Grebitus, C. (2014). Risk preferences and purchase of energy-efficient technologies in the residential sector. Ecological Economics, 107, 216-229.

Ramos, A., Labandeira, X., \& Löschel, A. (2016). Proenvironmental households and energy efficiency in Spain. Environmental and Resource Economics, 63(2), 367-393.

Rodriguez-Lara, I., \& Ponti, G. (2017). Social motives vs social influence: an experiment on interdependent time preferences. Games and Economic Behavior, 105(Supplement C), 177194.

Sallee, J. M. (2014). Rational inattention and energy efficiency. The Journal of Law and Economics, 57(3), 781-820.

Sallee, J. M., West, S. E., \& Fan, W. (2016). Do consumers recognize the value of fuel economy? Evidence from used car prices and gasoline price fluctuations. Journal of Public Economics, 135, 61-73.

Samuelson, W., \& Zeckhauser, R. (1988). Status quo bias in decision making. Journal of Risk and Uncertainty, 1(1), 759.

Schleich, J., Gassmann, X., Faure, C., \& Meissner, T. (2016). Making the implicit explicit: a look inside the implicit discount rate. Energy Policy, 97, 321-331.

Schultz, P. W., Nolan, J. M., Cialdini, R. B., Goldstein, N. J., \& Griskevicius, V. (2007). The constructive, destructive, and reconstructive power of social norms. Psychological Science, 18(5), 429-434. 
Schwartz, S. (1992). Universal in the content and structure of values: theoretical advances and empirical tests in 20 countries. Advances in Experimental Social Psychology, 25, 1-65.

Schwartz, D., de Bruin, W. B., Fischhoff, B., \& Lave, L. (2015). Advertising energy saving programs: the potential environmental cost of emphasizing monetary savings. Journal of Experimental Psychology: Applied, 21(2), 158-166.

Sexton, S. E., \& Sexton, A. (2014). Conspicuous conservation: the Prius halo and willingness to pay for environmental bona fides. Journal of Environmental Economics and Management, 67(3), 303-317.

Simon, H. A. (1982). Models of bounded rationality. Cambridge: MIT Press.

Sorrell, S., Dimitropoulos, J., \& Sommerville, M. (2009). Empirical estimates of the direct rebound effect: a review. Energy Policy, 37(4), 1356-1371.

Sovacool, B. K., \& Hess, D. J. (2017). Ordering theories: typologies and conceptual frameworks for sociotechnical change. Social Studies of Science, 47(5), 703-750.

Steg, L., \& De Groot, J. I. M. (2012). Environmental values. In S. D. Clayton (Ed.), The Oxford handbook of environmental and conservation psychology. Oxford: Oxford University Press.

Steg, L., Bolderdijk, J. W., Keizer, K., \& Perlaviciute, G. (2014). An integrated framework for encouraging pro-environmental behaviour: the role of values, situational factors and goals. Journal of Environmental Psychology, 38, 104-115.

Steg, L., Perlaviciute, G., \& van der Werff, E. (2015). Understanding the human dimensions of a sustainable energy transition. Frontiers in Psychology, 6, 805.

Stern, P. C., Janda, K. B., Brown, M. A., Steg, L., Vine, E. L., \& Lutzenhiser, L. (2016). Opportunities and insights for reducing fossil fuel consumption by households and organizations. Nature Energy, 1(5), 16043.

Strotz, R. H. (1955). Myopia and inconsistency in dynamic utility maximization. The Review of Economic Studies, 23(3), 165180.

Sutter, M., Kocher, M. G., Glätzle-Rützler, D., \& Trautmann, S. T. (2013). Impatience and uncertainty: experimental decisions predict adolescents' field behavior. American Economic Review, 103(1), 510-531.

Tao, J., \& Yu, S. (2011). Implementation of energy efficiency standards of household refrigerator/freezer in China: potential environmental and economic impacts. Applied Energy, 88(5), 1890-1905.

Taufik, D., Bolderdijk, J. W., \& Steg, L. (2016). Going green? The relative importance of feelings over calculation in driving environmental intent in the Netherlands and the United States. Energy Research \& Social Science, 22, 52-62.

Thaler, R. H., \& Sunstein, C. R. (2008). Nudge: improving decisions about health, wealth, and happiness. Yale University Press.

Tsvetanov, T., \& Segerson, K. (2014). The welfare effects of energy efficiency standards when choice sets matter. Journal of the Association of Environmental and Resource Economists, 1(1/2), 233-271.

Tversky, A., \& Kahneman, D. (1974). Judgment under uncertainty: heuristics and biases. Science, 185(4157), 1124-1131.

Ungemach, C., Camilleri, A. R., Johnson, E. J., Larrick, R. P., \& Weber, E. U. (2017). Translated attributes as choice architecture: aligning objectives and choices through decision signposts. Management Science, 64(5), 1975-2471.

van der Werff, E., Steg, L., \& Keizer, K. (2013). The value of environmental self-identity: the relationship between biospheric values, environmental self-identity and environmental preferences, intentions and behaviour. Journal of Environmental Psychology, 34, 55-63.

Wagner, K. (2016). Environmental preferences and consumer behavior. Economics Letters, 149, 1-4.

Ward, D. O., Clark, C. D., Jensen, K. L., Yen, S. T., \& Russell, C. S. (2011). Factors influencing willingness-to-pay for the ENERGY STAR@ label. Energy Policy, 39(3), 1450-1458.

Weber, B. J., \& Chapman, G. B. (2005). Playing for peanuts: Why is risk seeking more common for low-stakes gambles? Organizational Behavior and Human Decision Processes, 97(1), 31-46.

Wilson, C., \& Dowlatabadi, H. (2007). Models of decision making and residential energy use. Annual Review of Environment and Resources, 32(1), 169-203. 